Article

\title{
Hardening Embrittlement and Non-Hardening Embrittlement of Welding-Heat-Affected Zones in a Cr-Mo Low Alloy Steel
}

\author{
Yu Zhao ${ }^{1}$, Qing Ma ${ }^{1,2}$ and Shenhua Song ${ }^{1, *}$ \\ 1 Shenzhen Key Laboratory of Advanced Materials, School of Materials Science and Engineering, \\ Harbin Institute of Technology, Shenzhen 518055, China; zhaoyu0816@126.com (Y.Z.); \\ wustmq@163.com (Q.M.) \\ 2 Research Institute of Tsinghua University in Shenzhen, Shenzhen 518057, China \\ * Correspondence: shsong@hit.edu.cn; Tel.: +86-755-2603-3465
}

Received: 8 May 2018; Accepted: 27 May 2018; Published: 1 June 2018

\begin{abstract}
The embrittlement of heat affected zones (HAZs) resulting from the welding of a P-doped 2.25Cr-1Mo steel was studied by the analysis of the fracture appearance transition temperatures (FATTs) of the HAZs simulated under a heat input of $45 \mathrm{~kJ} / \mathrm{cm}$ with different peak temperatures. The FATTs of the HAZs both with and without tempering increased with the rise of the peak temperature. However, the FATTs were apparently lower for the tempered HAZs. For the as-welded (untempered) HAZs, the FATTs were mainly affected by residual stress, martensite/austenite $(\mathrm{M} / \mathrm{A})$ islands, and bainite morphology. The observed embrittlement is a hardening embrittlement. On the other hand, the FATTs of the tempered HAZs were mainly affected by phosphorus grain boundary segregation, thereby causing a non-hardening embrittlement. The results demonstrate that the hardening embrittlement of the as-welded HAZs was more severe than the non-hardening embrittlement of the tempered HAZs. Consequently, a post-weld heat treatment should be carried out if possible so as to eliminate the hardening embrittlement.
\end{abstract}

Keywords: welding; heat-affected zone; segregation; embrittlement

\section{Introduction}

2.25Cr-1Mo steel, with a high temperature creep resistance, is one of the most important Cr-Mo low alloy steels, and is widely used in the power industry, where high temperatures and pressures are involved [1]. Owing to the high capacity of power plants, the pressure vessel should be made of the steel with a thick wall. Therefore, a high heat input welding needs to be employed to ensure high efficiency during the manufacturing of pressure vessels [2]. Unfortunately, the embrittlement of the weld joint induced by high heat input welding is a serious problem [2,3]. The performance of the fusion zone may be improved by metallurgy during welding, but this is impossible for the heat-affected zone (HAZ) [4]. Consequently, close attention should be paid to the embrittlement of HAZs in 2.25Cr-1Mo steel.

The combined hardening and non-hardening embrittlement of interstitial-free steel has been investigated in a previous study [5]. The research shows that the brittleness of the steel is related to its yield strength, grain size and the grain boundary segregation of impurity atoms. In addition, a recent investigation concerning the embrittlement of quenched and tempered 2.25Cr-1Mo steel [6] demonstrated that the fracture appearance transition temperature (FATT) of the steel was directly correlated to the yield strength and impurity grain boundary segregation. The prior austenite grain size was not directly linked to the FATT, but it influenced both the yield strength and impurity grain boundary segregation. It can be reasonably anticipated that the embrittlement of HAZs is in correlation 
to hardening, microstructure coarsening and impurity boundary segregation, which could be affected by the welding thermal cycle and the subsequent service condition [2,7-11]. Hence, the toughness of HAZs could be deteriorated by both hardening embrittlement and non-hardening embrittlement. Hardening embrittlement is caused by hardening, such as strain hardening, solid solution hardening, and precipitation hardening, which increases with the increasing yield strength of the material. Non-hardening embrittlement is induced by the grain boundary segregation of some impurities such as $\mathrm{P}, \mathrm{Sb}, \mathrm{Sn}$ and As. This embrittlement becomes more and more serious with the enhancement of the impurity grain boundary segregation.

Some studies have indicated that the peak temperature of the welding thermal cycle is related to the distance from the HAZ to the fusion line [8,12-14]. Hence, there should be different combinations of microstructure, residual stress, grain size, and impurity boundary segregation in the HAZs at different positions. The objective of the present work is to systematically study the toughness deteriorations of as-welded and tempered HAZs in a 2.25Cr-1Mo steel, simulated with a constant high input but with different peak temperatures. The embrittlement mechanisms will be clarified by analyzing the microstructures, hardness, and phosphorus segregation of the HAZs.

\section{Experimental Procedure}

The experimental steel was prepared by vacuum induction melting and the ingot (50 kg) was hot rolled into a plate $16 \mathrm{~mm}$ in thickness. The chemical composition of the steel is shown in Table 1 . Blocks with a size of $12 \mathrm{~mm} \times 12 \mathrm{~mm} \times 75 \mathrm{~mm}$ were machined from the plate, and then austenitized at $960{ }^{\circ} \mathrm{C}$ and oil quenched, followed by tempering for $2 \mathrm{~h}$ at $650{ }^{\circ} \mathrm{C}$. Therefore, the material had the unified microstructure of tempered martensite before weld thermal cycling. After the above heat treatment, all blocks were machined into specimens with a size of $11 \mathrm{~mm} \times 11 \mathrm{~mm} \times 70 \mathrm{~mm}$ for subsequent welding thermal simulations.

Table 1. The chemical composition of the experimental 2.25Cr-1Mo steel.

\begin{tabular}{ccccccccc}
\hline Element & $\mathbf{C}$ & $\mathbf{S i}$ & $\mathbf{M n}$ & $\mathbf{C r}$ & $\mathbf{M o}$ & $\mathbf{P}$ & $\mathbf{S}$ & $\mathbf{F e}$ \\
\hline wt $\%$ & 0.11 & 0.2 & 0.51 & 2.32 & 1.1 & 0.049 & 0.007 & Bal. \\
at $\%$ & 0.511 & 0.399 & 0.518 & 2.489 & 0.64 & 0.088 & 0.012 & Bal. \\
\hline
\end{tabular}

A Gleeble-1500D thermal simulator was employed to simulate the welding thermal cycles with a fixed heat input of $45 \mathrm{~kJ} / \mathrm{cm}$ at several peak temperatures $\left(1000{ }^{\circ} \mathrm{C}, 1100{ }^{\circ} \mathrm{C}, 1200{ }^{\circ} \mathrm{C}\right.$, and $\left.1320{ }^{\circ} \mathrm{C}\right)$. This heat input was used to characterize the submerged arc welding [2], and the different peak temperatures were selected to simulate different distinct regions of the HAZ [8]. Although the thermal simulation is hard to simulate due to the temperature gradient in a HAZ, it is still an optimal method to study some local regions of the HAZ. The thermal cycling simulations were performed according to the Rokalin- two dimension mode and the obtained thermal curves are shown in Figure 1. As can be seen, when the heat input was fixed, the thermal cycles almost had the same cooling rate, i.e., the cooling times from 800 to $500{ }^{\circ} \mathrm{C}\left(t_{8 / 5}\right)$ were all approximately $27 \mathrm{~s}$ under different peak temperatures. After the thermal simulations, half of the specimens were tempered for $800 \mathrm{~h}$ at $520^{\circ} \mathrm{C}$.

The metallographic structures of the HAZs were observed after polishing and chemical etching. The average grain sizes were determined by the linear intercept method. A Vickers hardness tester was employed to measure the hardness of the specimens.

A grain boundary microanalysis was performed with the use of a field emission gun scanning transmission electron microscope (FEGSTEM, JEM-2100F, JOEL CO., Ltd., Tokyo, Japan) equipped with an energy dispersive spectrometer (EDS, Oxford INCA, Oxford, UK). Figure 2 shows a typical image of a grain boundary analyzed by FEGSTEM-EDS. Obviously, there was no precipitate present around the grain boundary and meanwhile the incident electron beam was well parallel to the boundary, which is necessary for grain boundary microanalysis. However, as the special resolution of FEGSTEM-EDS 
(often greater than $2 \mathrm{~nm}$ [15]) rarely approximates the grain boundary thickness (less than $1 \mathrm{~nm}$ [16]), the measured result should be a convolution value of the actual compositional distribution near the grain boundary. For this reason, the measured results were corrected by a convolution method and the details of the correction for the measured values can be seen elsewhere [17-19].

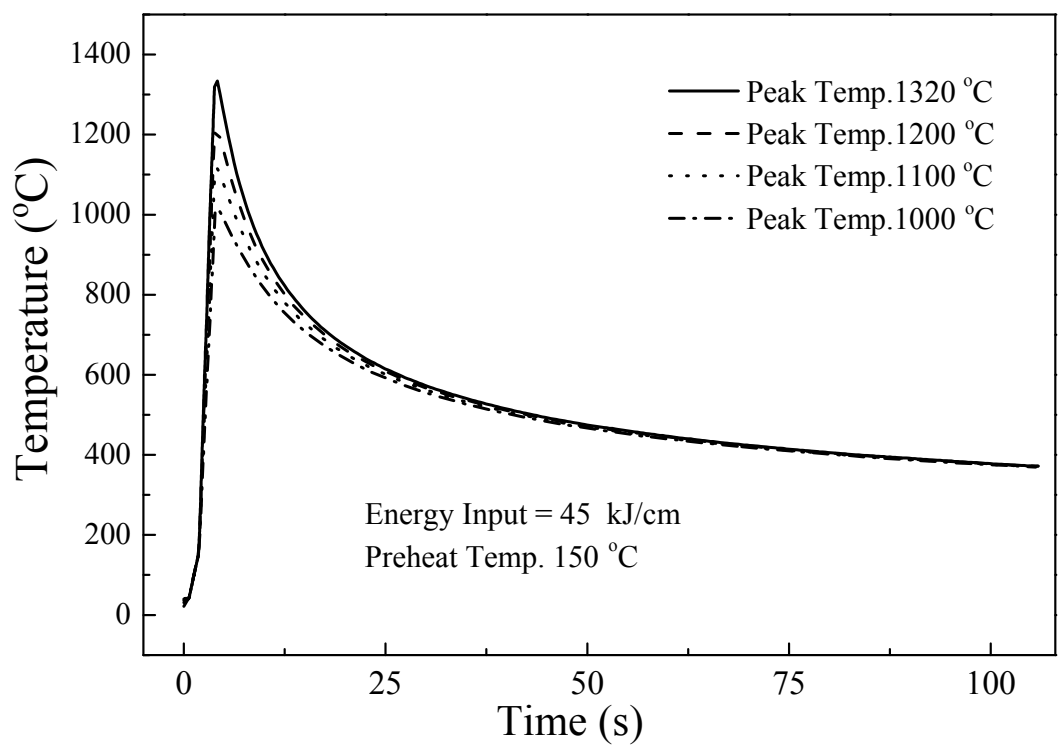

Figure 1. Thermal curves with different peak temperatures.

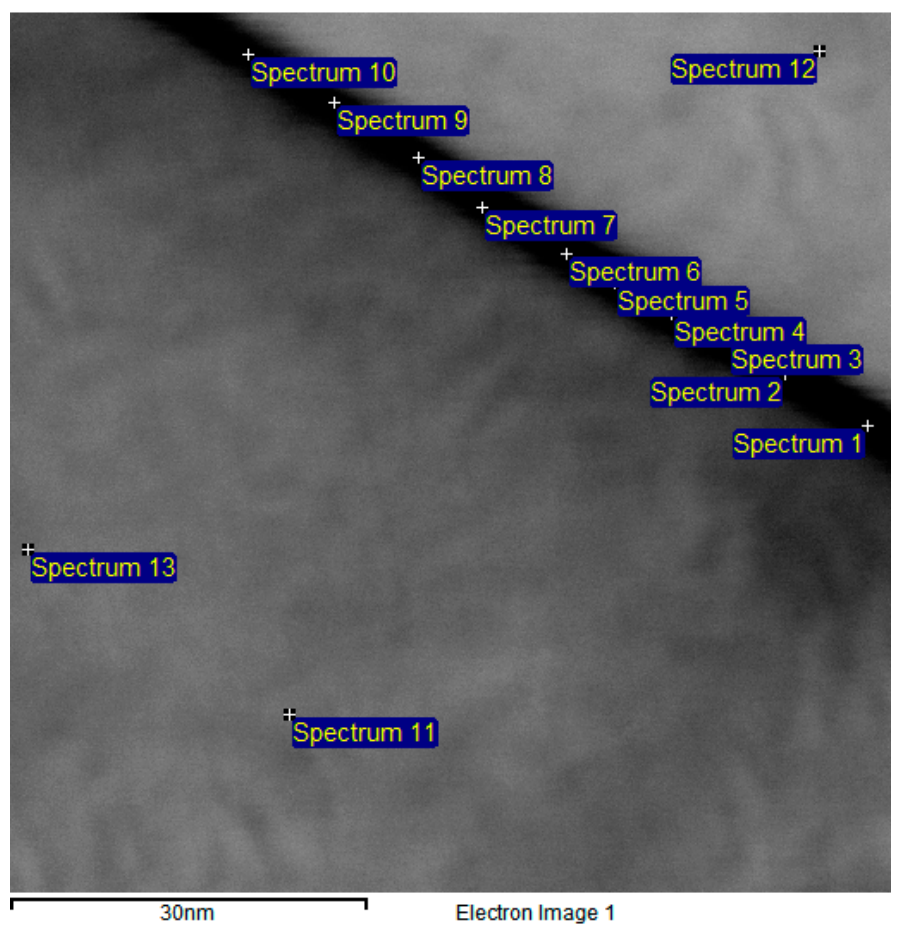

Figure 2. FEGSTEM image showing a typical grain boundary analyzed.

The fracture appearance transition temperatures (FATTs) of the HAZs were determined by Charpy impact tests combined with fracture appearance observations with the use of scanning electron microscopy (SEM, HITACHI S4700, Tokyo, Japan). The mini-Charpy specimens, $2.5 \mathrm{~mm}$ $\times 2.5 \mathrm{~mm} \times 55 \mathrm{~mm}$ in dimension, with a $0.8 \mathrm{~mm}$-deep sharp V-notch were adopted to measure the FATTs. The V-notches were located in the simulated HAZs. The mini-Charpy impact test was 
performed at different temperatures and the FATT was determined by analyzing the fracture surfaces, which corresponds to $50 \%$ brittle fracture. For each FATT, about 16 specimens were used.

\section{Results and Discussion}

\subsection{Microstructure and Hardness}

Figure 3 shows the metallographs of the as-welded and tempered HAZs simulated with different peak temperatures. Figure $3 \mathrm{a}, \mathrm{c}, \mathrm{e}, \mathrm{g}$ correspond to the as-welded specimens simulated with the peak temperatures of $1000{ }^{\circ} \mathrm{C}, 1100{ }^{\circ} \mathrm{C}, 1200{ }^{\circ} \mathrm{C}, 1320{ }^{\circ} \mathrm{C}$, respectively. The corresponding tempered microstructures are shown in Figure $3 b, d, f, h$, respectively. As can be seen, the microstructures of the as-welded HAZs consisted of allotriomorphic ferrite (AF), granular bainite (GB) and lath bainite (LB), while some of the bainite dissolved into the matrix after tempering. There was more granular bainite in the HAZs with lower peak temperatures $\left(1000^{\circ} \mathrm{C}\right.$ and $\left.1100{ }^{\circ} \mathrm{C}\right)$, whereas the lath bainite was preferentially formed in the as-welded HAZs with higher peak temperatures $\left(1200{ }^{\circ} \mathrm{C}\right.$ and $\left.1320^{\circ} \mathrm{C}\right)$. Nevertheless, the tempered HAZs almost had a uniform microstructure no matter how high the peak temperature.
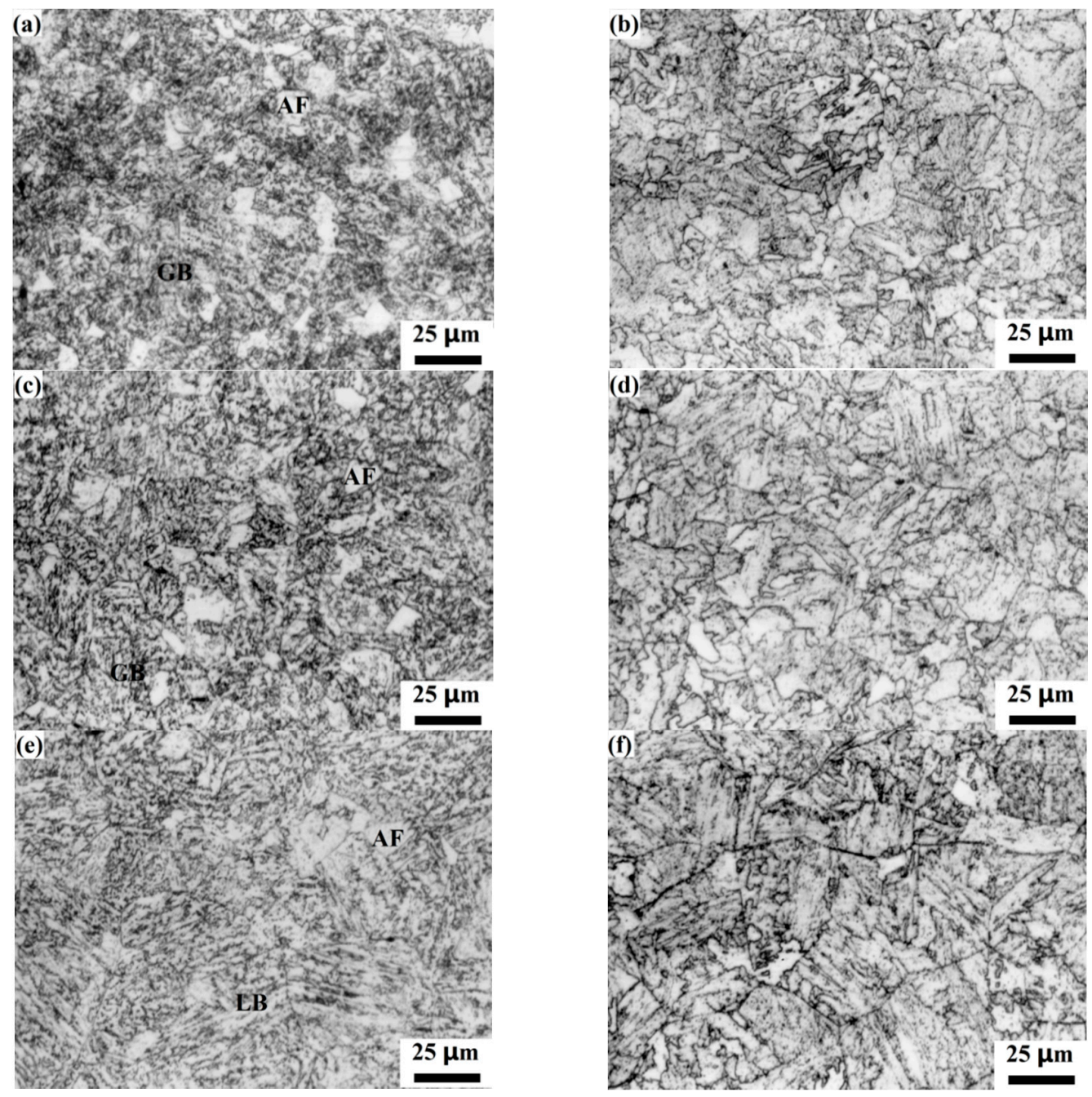

Figure 3. Cont. 

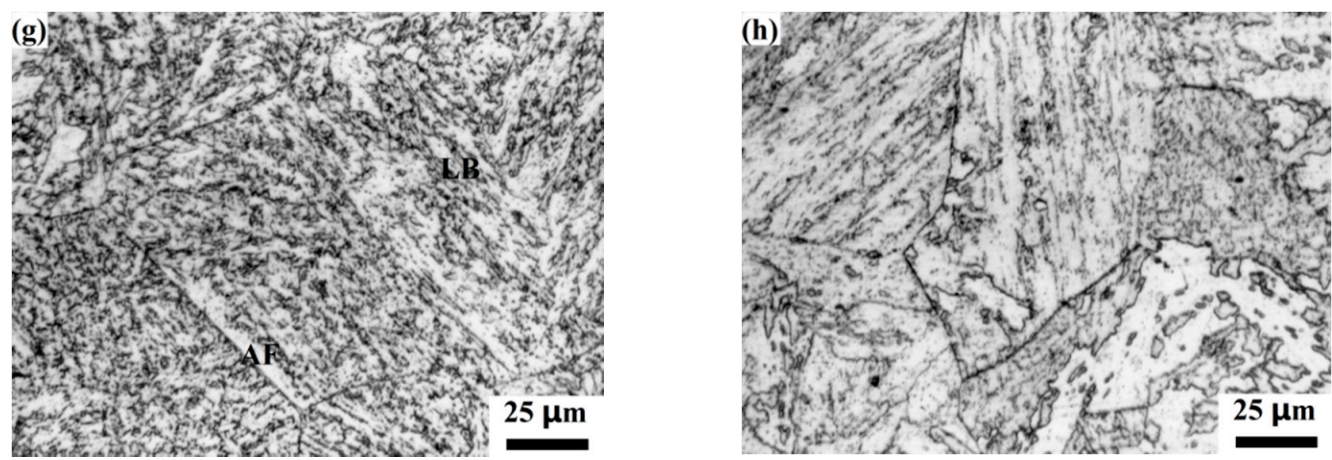

Figure 3. Metallographs of the as-welded and tempered heat-affected zones obtained with different peak temperatures: (a) $1000{ }^{\circ} \mathrm{C}$ (as-welded); (b) $1000{ }^{\circ} \mathrm{C}$ (tempered); (c) $1100{ }^{\circ} \mathrm{C}$ (as-welded); (d) $1100{ }^{\circ} \mathrm{C}$ (tempered); (e) $1200^{\circ} \mathrm{C}$ (as-welded); (f) $1200{ }^{\circ} \mathrm{C}$ (tempered); (g) $1320^{\circ} \mathrm{C}$ (as-welded); and (h) $1320^{\circ} \mathrm{C}$ (tempered).

Figure 4 shows the transmission electron microscopy (TEM) morphologies of the as-welded and tempered HAZs with different peak temperatures. The specimen condition for each image in Figure 4 is the same as that in Figure 3. A study by Zheng et al. [2] confirmed the existence of martensite/austenite $(\mathrm{M} / \mathrm{A})$ islands in coarse-grained HAZs with some high heat inputs $(36-60 \mathrm{~kJ} / \mathrm{cm})$ for $2.25 \mathrm{Cr}-1 \mathrm{Mo}$ steel. The TEM morphologies of the M/A islands were in accordance with those shown in Figure 4a,c,e,g. It was found that the $\mathrm{M} / \mathrm{A}$ islands became bigger when the welding thermal cycle had a higher peak temperature. On the other hand, all the M/A islands disappeared after tempering for $800 \mathrm{~h}$ at $520^{\circ} \mathrm{C}$, as shown in Figure $4 \mathrm{~b}, \mathrm{~d}, \mathrm{f}, \mathrm{h}$. Meanwhile, some fine carbide particles precipitated from the matrix in the tempered HAZs.
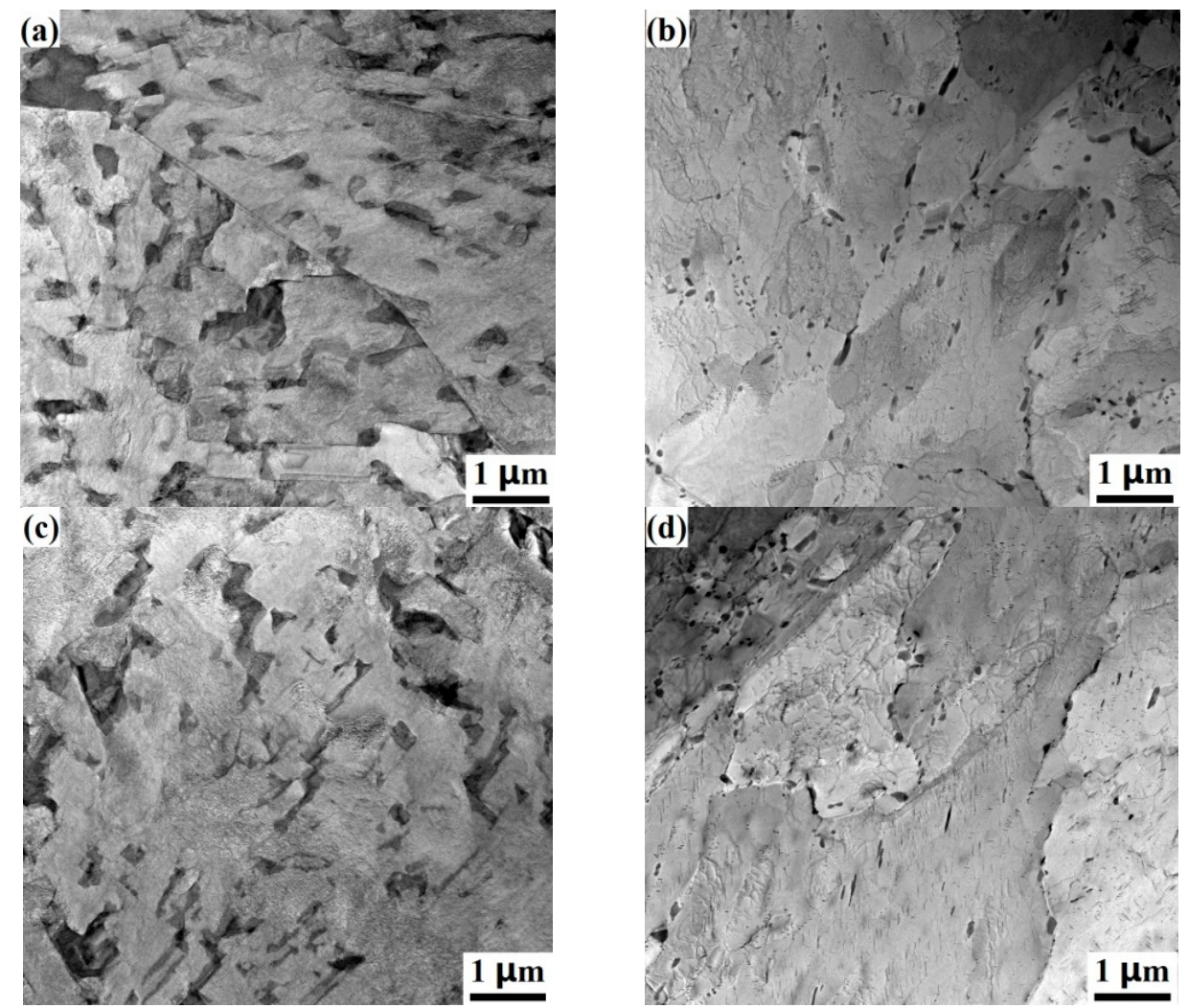

Figure 4. Cont. 

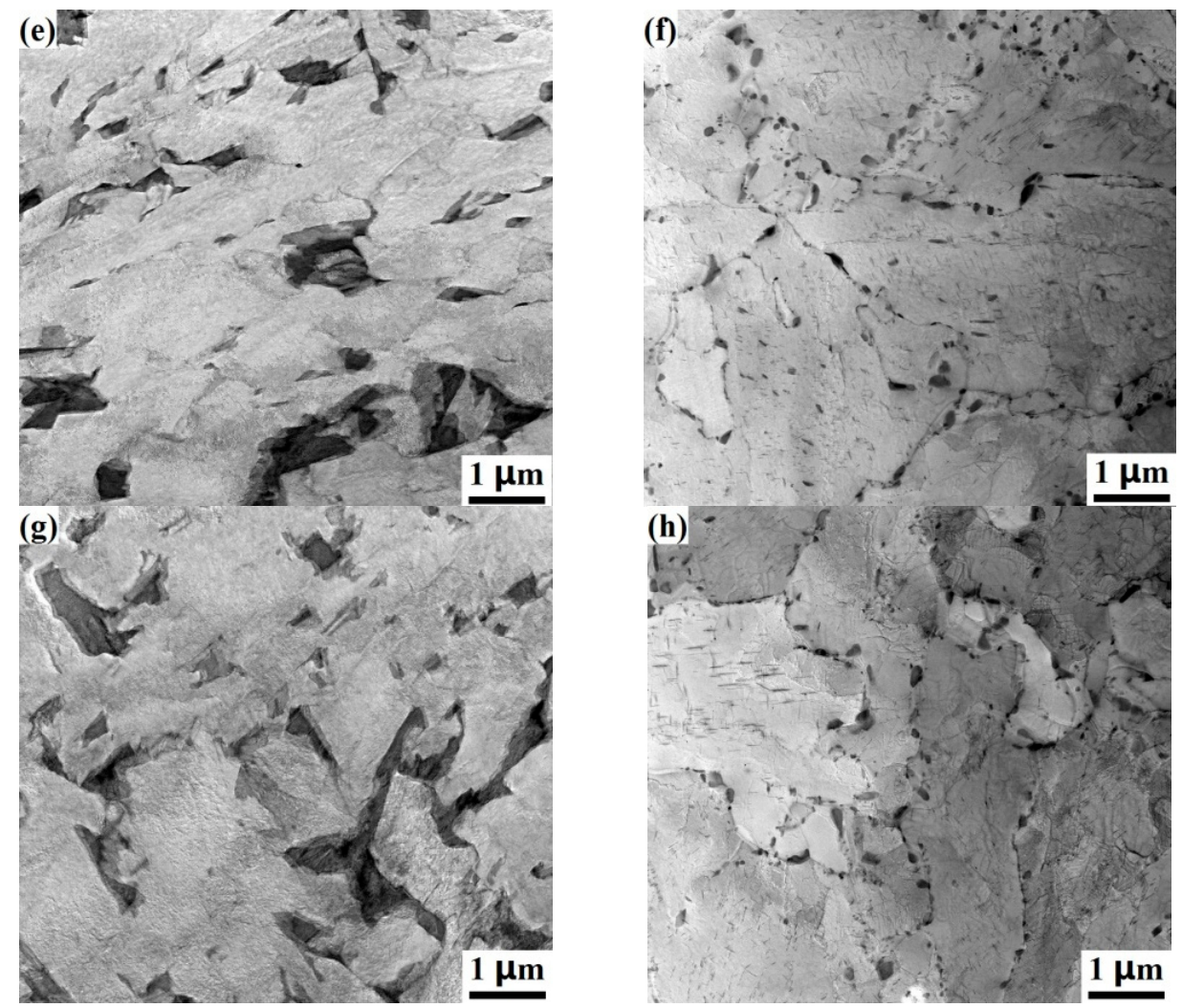

Figure 4. TEM morphologies of the as-welded and tempered specimens simulated with different peak temperatures: (a) $1000{ }^{\circ} \mathrm{C}$ (as-welded); (b) $1000{ }^{\circ} \mathrm{C}$ (tempered); (c) $1100{ }^{\circ} \mathrm{C}$ (as-welded); (d) $1100{ }^{\circ} \mathrm{C}$ (tempered); (e) $1200{ }^{\circ} \mathrm{C}$ (as-welded); (f) $1200{ }^{\circ} \mathrm{C}$ (tempered); (g) $1320^{\circ} \mathrm{C}$ (as-welded); (h) $1320^{\circ} \mathrm{C}$ (tempered).

Previous investigations indicated that the prior austenite grain size of some low alloy steels was related to its austenitizing temperature [20-22]. In the same way, the grain size of the HAZ could be affected by the peak temperature during the welding thermal cycle [14]. Figure 5 shows the metallographs of HAZs prepared after grain boundary etching. Clearly, the prior austenite grain size increased with the rise of the peak temperature, which were, as determined by the linear intercept method, approximately $9 \mu \mathrm{m}, 18 \mu \mathrm{m}, 40 \mu \mathrm{m}$, and $59 \mu \mathrm{m}$ for the peak temperatures of $1000{ }^{\circ} \mathrm{C}, 1100{ }^{\circ} \mathrm{C}$, $1200{ }^{\circ} \mathrm{C}$, and $1320^{\circ} \mathrm{C}$, respectively.
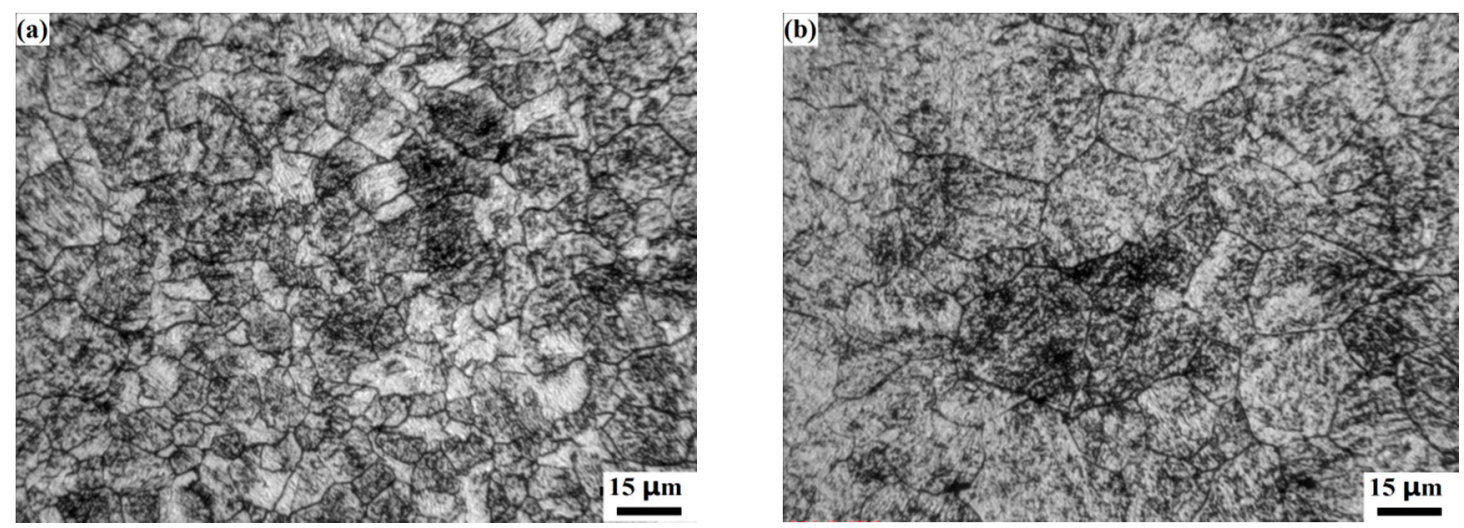

Figure 5. Cont. 

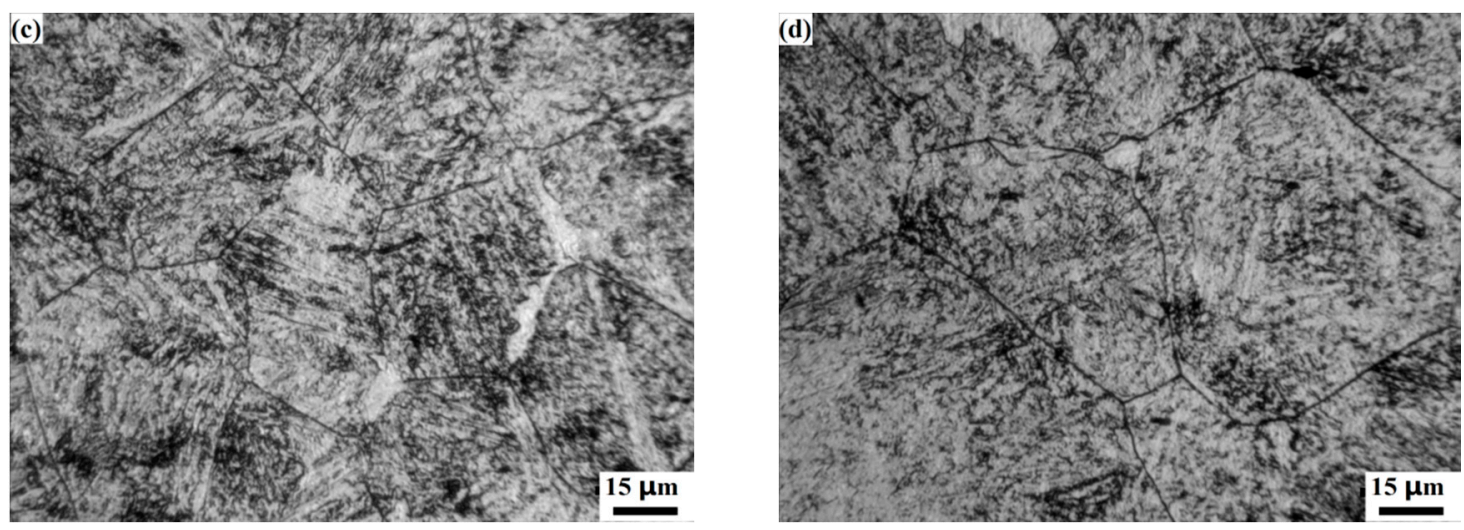

Figure 5. Different grain sizes in the heat-affected zones obtained with different peak temperatures: (a) $1000{ }^{\circ} \mathrm{C}$ and $9 \mu \mathrm{m}$; (b) $1100{ }^{\circ} \mathrm{C}$ and $18 \mu \mathrm{m}$; (c) $1200{ }^{\circ} \mathrm{C}$ and $40 \mu \mathrm{m}$; and (d) $1320^{\circ} \mathrm{C}$ and $59 \mu \mathrm{m}$.

Table 2 shows the Vickers hardness values of the as-welded and tempered HAZs simulated with different peak temperatures. It is obvious that the hardness is independent of the peak temperature for both the as-welded and tempered HAZs. In general, the welding residual stress, grain size, and microstructure could have affected the hardness of the HAZs. Although the welding residual stress, the proportion of lath bainite, the prior austenite grain size as well as the M/A island size all increased with the increasing peak temperature, they had different effects on the hardness of the HAZs. Firstly, the residual stress was positively related to the hardness $[10,23]$. Secondly, the lath bainite had a higher dislocation density compared to the granular bainite, so that the lath bainite was a harder phase [24,25]. Thirdly, according to the Hall-Petch relation [26,27], the finer grains yielded a higher strength, leading to a higher hardness. Finally, the M/A islands, which acted like precipitates, influenced the hardness by means of the precipitation hardening mechanism. A previous study showed that the precipitation strengthening effect decreased with increasing precipitate size if the precipitate radius was large enough $(>10 \mathrm{~nm})$ [28]. Therefore, the finer the $\mathrm{M} / \mathrm{A}$ islands, the stronger the precipitation hardening effect in the HAZs. In summary, the welding residual stress and lath bainite had positive effects, while the grain and M/A island sizes had a negative influence on the hardness of the HAZs. From this point of view, the hardness of the HAZs without tempering could be kept constant under the combined influence of these factors.

Table 2. Vickers hardness values of the as-welded and tempered heat-affected zones obtained with different peak temperatures.

\begin{tabular}{ccccc}
\hline Peak Temperature $\left({ }^{\circ} \mathbf{C}\right)$ & $\mathbf{1 0 0 0}$ & $\mathbf{1 1 0 0}$ & $\mathbf{1 2 0 0}$ & $\mathbf{1 3 2 0}$ \\
\hline As-welded & 334 & 339 & 338 & 338 \\
Tempered & 213 & 218 & 215 & 218 \\
\hline
\end{tabular}

On the other hand, the residual stress can be relieved during tempering. Besides, the M/A islands were almost fully dissolved in the tempered HAZs (see Figure 4). However, the grain size increased apparently with increasing peak temperature (see Figure 5) and the lath structure was faintly visible in the HAZs with higher peak temperatures (see Figure 3). As the effects of these two factors on the hardness were opposite, the hardness of the tempered HAZs also remained independent of the peak temperature.

Furthermore, the fact that the hardness values of the tempered HAZs were much lower than those of the untempered HAZs should be due to the disappearance of some hardening factors (residual stress, M/A islands, supersaturated dislocations) in the tempered HAZs. Nevertheless, it is noteworthy that the difference in yield strength may be more remarkable than that in hardness for low alloy steels [5]. 
Hence, the Vickers hardness is not a unique indication of the hardening (or strengthening) effect of the steel.

\subsection{Grain Boundary Segregation of Phosphorus}

The analysis results of phosphorus grain boundary segregation in the HAZs are illustrated in Figure 6. As can be seen, the segregation concentrations in the tempered HAZs were much higher than those in the untempered HAZs. A study by Zheng et al. [18] showed that the phosphorus segregation during the welding thermal cycle was not apparent due to the very short cooling time. The segregation in the untempered HAZs was mainly non-equilibrium segregation and increased somewhat with the increasing welding peak temperature, as shown in Figure 6 [29]. In contrast, the segregation in the tempered HAZs reached equilibrium after the long-term treatment $(800 \mathrm{~h})$ at $520{ }^{\circ} \mathrm{C}$ [30]. The equilibrium segregation level usually increased with the increasing grain size [31] and normally the equilibrium segregation at lower temperatures was much larger than the non-equilibrium segregation (see Figure 6).

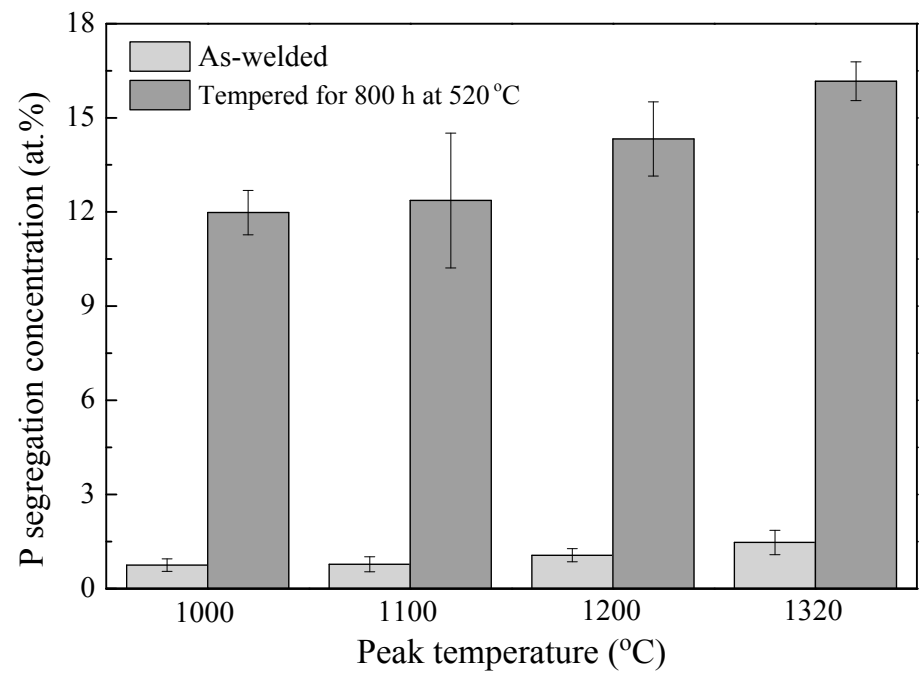

Figure 6. Phosphorus grain boundary segregation concentrations in the as-welded and tempered heat-affected zones obtained with different peak temperatures, determined by FEGSTEM-EDS microanalysis (error bars represent the $95 \%$ confidence intervals).

\subsection{Hardening Embrittlement and Non-Hardening Embrittlement of As-Welded and Tempered HAZs}

The fracture appearance transition temperatures (FATTs) of the HAZs are shown in Figure 7. As seen, the FATT increased with the increasing peak temperature for both the as-welded and tempered HAZs. Besides, the FATTs of the as-welded HAZs were always higher than those of the tempered HAZs for the same peak temperature.

For the as-welded (untempered) HAZs, the FATTs were mainly affected by the microstructure and welding residual stress. It has been reported that the lattice mismatch between the M/A island and the surrounding ferrite matrix acts as an initiation of the stress concentration when the steel suffers from an impact load [32,33]. Moreover, the high welding residual stress was another cause for the deterioration of the toughness [10]. In contrast, the opposite influence of the grain coarsening on the toughness of the HAZs was rather weak. Consequently, the FATT had the same variation tendency with the M/A size and residual stress in the as-welded HAZs. The embrittlement mechanism can be reflected by the fracture appearance. The fractographs in Figure 8 show the fracture surface of an as-welded HAZ broken by impact at the temperature close to its FATT. As seen, the brittle part of the fracture was absolutely the cleavage type, indicating that the embrittlement was mainly in connection 
with some strain barriers. Therefore, the toughness of the as-welded HAZ deteriorated mainly due to hardening embrittlement.

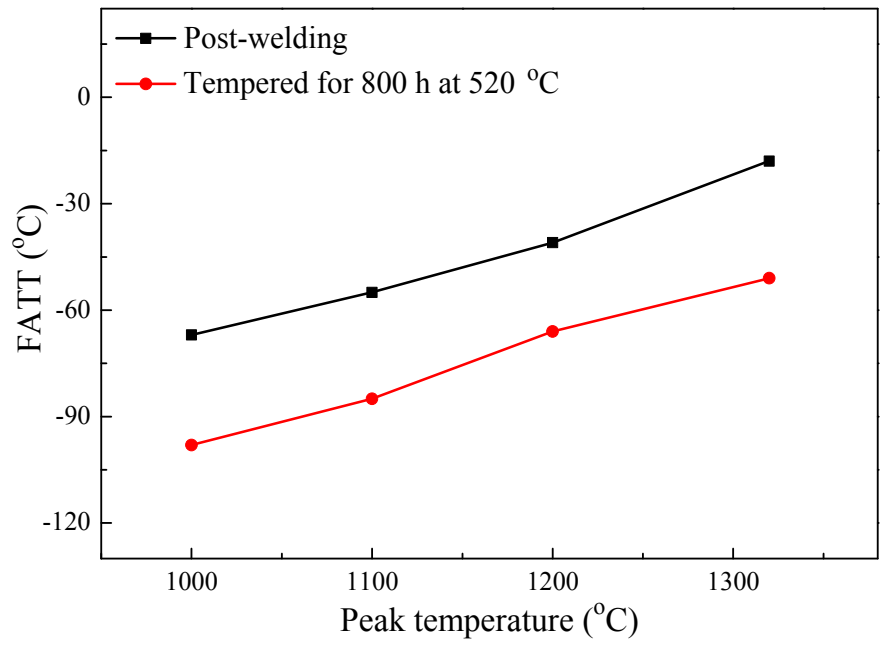

Figure 7. Fracture appearance transition temperatures (FATTs) of the as-welded and tempered heat-affected zones obtained with different peak temperatures.

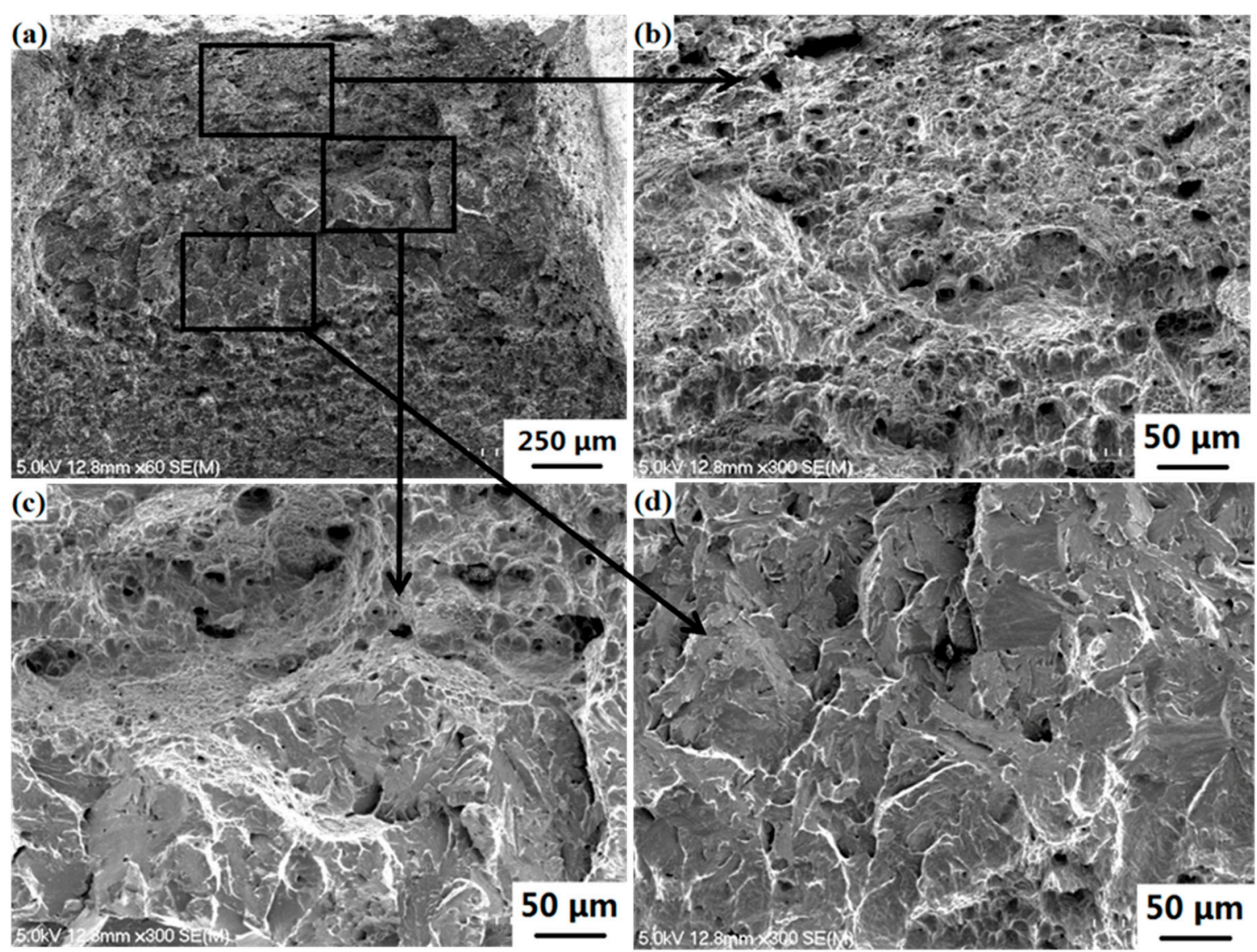

Figure 8. Fractographs of the as-welded HAZ obtained with a peak temperature of $1320^{\circ} \mathrm{C}$ and broken by impact at $-20^{\circ} \mathrm{C}$ : (a) the whole section; (b) the local ductile part; (c) the local mixed brittle-ductile part; and (d) the local brittle part. 
For the tempered HAZs, the FATTs were mainly affected by the grain boundary segregation of phosphorus. After tempering, the residual stress and some microstructures that were detrimental to the toughness were removed. Hence, the embrittlement of the tempered HAZs originated mainly from the grain boundary segregation of phosphorus. It is well known that the segregation of phosphorus can weaken grain boundaries and lead to the intergranular embrittlement of some low alloy steels [34,35]. This embrittlement mechanism could be verified from the fractographs shown in Figure 9. It is obvious that the brittle part of the tempered HAZ fracture surface belonged to the intergranular mode, which was different from that of the as-welded HAZs, as shown in Figure 8. Consequently, the embrittlement of the tempered HAZs was mainly non-hardening embrittlement.

Furthermore, Figure 7 illustrates that the embrittlement of the as-welded HAZs was much more serious than that of the tempered HAZs in each case. This means that the hardening embrittlement caused by some harmful microstructures ( $\mathrm{M} / \mathrm{A}$ islands and lath bainite) plays a dominant role in deteriorating the toughness of the HAZs for the $2.25 \mathrm{Cr}-1 \mathrm{Mo}$ low alloy steel. Therefore, if possible, a post-weld heat treatment should be conducted before service to enhance the toughness of the steel.
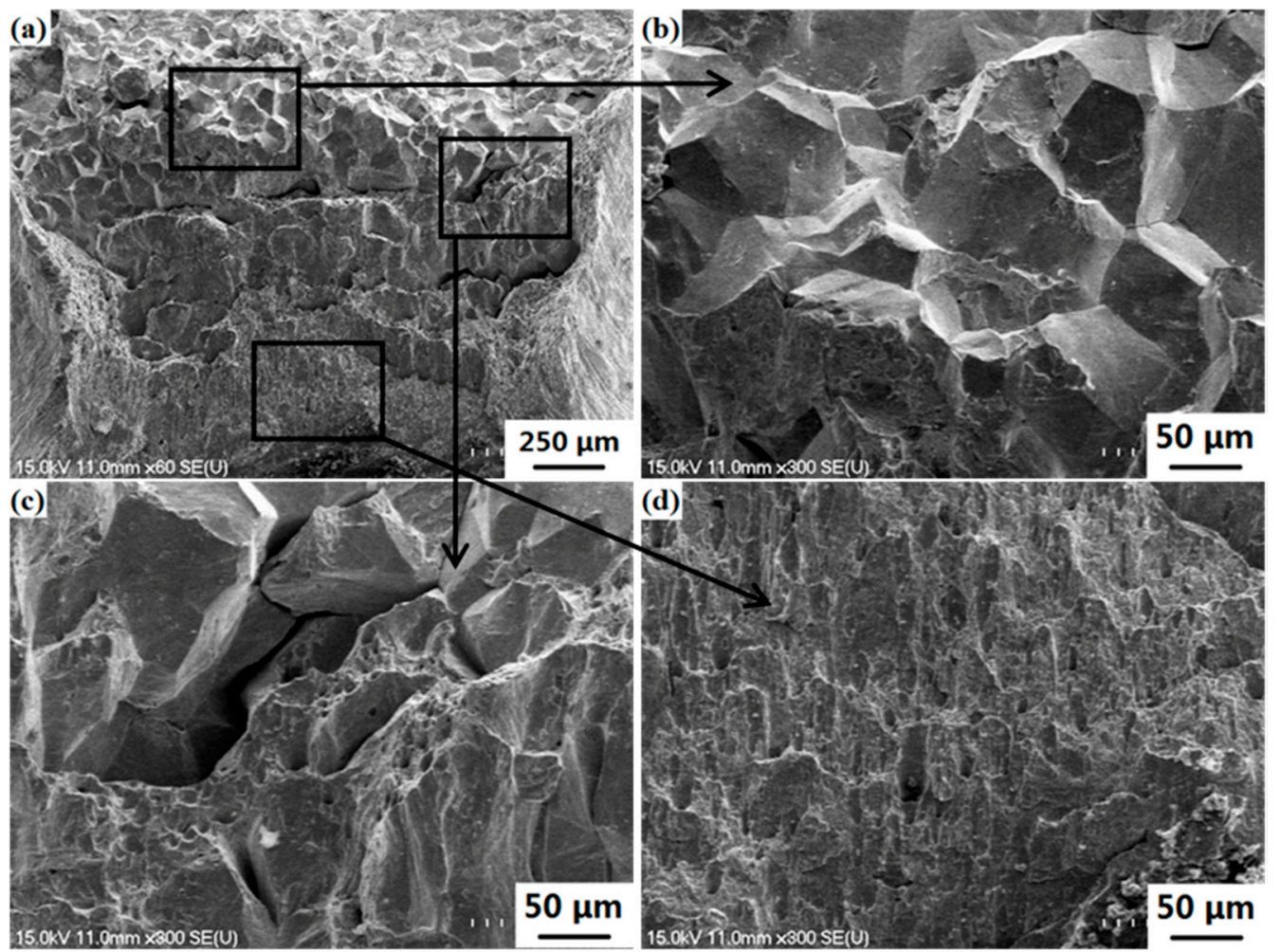

Figure 9. Fractographs of the tempered HAZ obtained with a peak temperature of $1320^{\circ} \mathrm{C}$ and broken by impact at $-45^{\circ} \mathrm{C}$ : (a) the whole section; (b) the local brittle part; (c) the local mixed brittle-ductile part; and (d) the local ductile part.

\section{Conclusions}

Hardening embrittlement induced by some deleterious microstructures occurred in the as-welded (untempered) HAZs of the experimental 2.25Cr-1Mo steel. The fracture appearance transition temperature (FATT) of the as-welded HAZs increased with the increasing peak temperature, which was mainly attributed to the coarsening of the M/A islands and the increasing of the lath bainite. On the other hand, the deterioration of the toughness of the tempered HAZ results were mainly from the grain boundary segregation of phosphorus and thus it belonged to non-hardening embrittlement. Moreover, the hardening embrittlement of the HAZs was apparently more severe than 
the non-hardening embrittlement. Therefore, a post-weld heat treatment is necessary for the secure service of the steel.

Author Contributions: Y.Z. mainly contributed to experimental work and result analysis; Q.M. mainly contributed to some experimental work; S.S. mainly contributed to research design and result analysis.

Acknowledgments: This work was supported by the Science and Technology Foundation of Shenzhen (Grant No. JCYJ20170307150808594) and the International Science \& Technology Cooperation Program of China (Grant No. 2014DFA53020).

Conflicts of Interest: The authors declare no conflict of interest.

\section{References}

1. Kang, D.H.; Lee, H.W. Microstructure and hardness change in high temperature service depending on Mo content in 2.25Cr-1Mo steel weld metals. Met. Mater. Int. 2011, 17, 963-967. [CrossRef]

2. Song, S.H.; Zheng, L. Effect of thermal cycling induced phosphorus grain boundary segregation on embrittlement of welding heat affected zones in 2.25Cr-1Mo steel. Mater. Sci. Technol. 2014, 30, 1378-1385. [CrossRef]

3. Dong, H.; Hao, X.; Deng, D. Effect of welding heat input on microstructure and mechanical properties of HSLA steel joint. Metallogr. Microstruct. Anal. 2014, 3, 138-146. [CrossRef]

4. Hutchinson, B.; Komenda, J.; Rohrer, G.S.; Beladi, H. Heat affected zone microstructures and their influence on toughness in two microalloyed HSLA steels. Acta Mater. 2015, 97, 380-391. [CrossRef]

5. Zhao, Y.; Song, S.H. An experiment-based model of combined hardening and non-hardening embrittlement in an interstitial free steel. Mater. Sci. Eng. A 2018, 721, 189-199. [CrossRef]

6. Zhao, Y.; Song, S.H. Combined effect of phosphorus grain boundary segregation, yield strength and grain size on embrittlement of a Cr-Mo low-alloy steel. Steel Res. Int. 2018. [CrossRef]

7. Wan, X.L.; Wu, K.M.; Huang, G.; Nune, K.C.; Li, Y.; Cheng, L. Toughness improvement by Cu addition in the simulated coarse-grained heat-affected zone of high-strength low-alloy steels. Sci. Technol. Weld. Join. 2016, 21, 295-302. [CrossRef]

8. Hu, J.; Du, L.X.; Xie, H.; Dong, F.T.; Misra, R.D.K. Effect of weld peak temperature on the microstructure, hardness, and transformation kinetics of simulated heat affected zone of hot rolled ultra-low carbon high strength Ti-Mo ferritic steel. Mater. Des. 2014, 60, 302-309. [CrossRef]

9. Li, Z.S.; Li, S.L.; Tian, L.; Zhang, X.H.; Liu, J.Z. Effect of post-weld heat treatment on carbide precipitation and impact properties of coarse-grained heat-affected zone of Q690 steel. Adv. Mater. Res. 2014, 989, 576-580. [CrossRef]

10. Aloraier, A.S.; Joshi, S.; Price, J.W.H.; Alawadhi, K. Hardness, microstructure and residual stresses in low carbon steel welding with post-weld heat treatment and temper bead welding. Metall. Mater. Trans. A 2014, 45, 2030-2037. [CrossRef]

11. Li, Y.L.; Fu, L.M.; Yu, L.K. Investigation of non-equilibrium grain boundary segregation on CGHAZ in reactor pressure vessel steel. Sci. Technol. Weld. Join. 2015, 20, 395-401. [CrossRef]

12. Sawada, K.; Hara, T.; Tabuchi, M.; Kimura, K.; Kubushiro, K. Microstructure characterization of heat affected zone after welding in Mod.9Cr-1Mo steel. Mater. Charact. 2015, 101, 106-113. [CrossRef]

13. Meng, W.; Li, Z.; Jiang, X.; Huang, J.; Wu, Y.; Katayama, S. Microstructure and toughness of simulated heat-affected zone of laser welded joint for 960 MPa grade high strength steel. J. Mater. Eng. Perform. 2014, 23, 3640-3648. [CrossRef]

14. Li, X.; Ma, X.; Subramanian, S.V.; Shang, C.; Misra, R.D.K. Influence of prior austenite grain size on martensite-austenite constituent and toughness in the heat affected zone of $700 \mathrm{MPa}$ high strength line pipe steel. Mater. Sci. Eng. A 2014, 616, 141-147. [CrossRef]

15. Keast, V.J.; Williams, D.B. Quantification of boundary segregation in the analytical electron microscope. J. Microsc. 2000, 199, 45-55. [CrossRef] [PubMed]

16. Peterson, N.L. Grain-boundary diffusion in metals. Metall. Rev. 1983, 28, 65-91. [CrossRef]

17. Faulkner, R.G.; Morgan, T.S.; Little, E.A. Analytical electron microscopy of thin segregated layers. X-ray Spectrom. 1994, 23, 195-202. [CrossRef] 
18. Zheng, L.; Song, S.H.; Yuan, Z.X. Grain boundary segregation of antimony in heat affected zones during welding thermal cycles for a Cr-Mo low alloy steel. Mater. Lett. 2013, 96, 152-154. [CrossRef]

19. Zheng, L.; Song, S.H. Antimony-induced embrittlement in welding heat-affected zones in a Cr-Mo low-alloy steel. Philos. Mag. Lett. 2013, 93, 405-412. [CrossRef]

20. Białobrzeska, B.; Konat, Ł.; Jasiński, R. The influence of austenite grain size on the mechanical properties of low-alloy steel with boron. Metals 2017, 1, 26. [CrossRef]

21. Hwang, B.; Kim, S. Grain size dependence of ductile-to-brittle transition temperature of a high-nitrogen Cr-Mn austenitic steel. Mater. Sci. Eng. A 2012, 531, 182-185. [CrossRef]

22. Khan, S.A.; Islam, M.A. Influence of prior austenite grain size on the degree of temper embrittlement in Cr-Mo steel. J. Mater. Eng. Perform. 2017, 16, 80-85. [CrossRef]

23. Bussu, G.; Irving, P.E. The role of residual stress and heat affected zone properties on fatigue crack propagation in friction stir welded 2024-T351 aluminium joints. Int. J. Fatigue 2003, 25, 77-88. [CrossRef]

24. He, S.H.; He, B.B.; Zhu, K.Y.; Huang, M.X. Evolution of dislocation density in bainitic steel: Modeling and experiments. Acta Mater. 2018, 149, 46-56. [CrossRef]

25. He, S.H.; He, B.B.; Zhu, K.Y.; Huang, M.X. On the correlation among dislocation density, lath thickness and yield stress of bainite. Acta Mater. 2017, 135, 382-389. [CrossRef]

26. Petch, N.J. The cleavage strength of polycrystals. J. Iron Steel Inst. 1953, 174, 25-28.

27. Hall, E.O. The deformation and ageing of mild steel: III discussion of results. Proc. Phys. Soc. 1951, 64, 747-753. [CrossRef]

28. Gladman, T. Precipitation hardening in metals. Met. Sci. J. 1999, 15, 30-36. [CrossRef]

29. Xu, T.D.; Song, S.H. A kinetic model of non-equilibrium grain-boundary segregation. Acta Meter. 1989, 37, 2499-2506. [CrossRef]

30. Wu, J.; Song, S.H.; Weng, L.Q.; Xi, T.H.; Yuan, Z.X. An Auger electron spectroscopy study of phosphorus and molybdenum grain boundary segregation in a 2.25Cr1Mo steel. Mater. Charact. 2008, 59, 261-265. [CrossRef]

31. Zhao, Y.; Song, S.H.; Si, H.; Wang, K. Effect of grain size on grain boundary segregation thermodynamics of phosphorus in interstitial-free and 2.25Cr-1Mo Steels. Metals 2017, 7, 470. [CrossRef]

32. Li, X.; Fan, Y.; Ma, X.; Subramanian, S.V.; Shang, C. Influence of martensite-austenite constituents formed at different intercritical temperatures on toughness. Mater. Des. 2015, 67, 457-463. [CrossRef]

33. Lan, L.; Qiu, C.; Song, H.; Zhao, D. Correlation of martensite-austenite constituent and cleavage crack initiation in welding heat affected zone of low carbon bainitic steel. Mater. Lett. 2014, 125, 86-88. [CrossRef]

34. Song, S.H.; Zhuang, H.; Wu, J.; Weng, L.Q.; Yuan, Z.X.; Xi, T.H. Dependence of ductile-to-brittle transition temperature on phosphorus grain boundary segregation for a 2.25Cr1Mo steel. Mater. Sci. Eng. A 2008, 486, 433-438. [CrossRef]

35. Gibson, M.A.; Schuh, C.A. Segregation-induced changes in grain boundary cohesion and embrittlement in binary alloys. Acta Mater. 2015, 95, 145-155. [CrossRef]

(C) 2018 by the authors. Licensee MDPI, Basel, Switzerland. This article is an open access article distributed under the terms and conditions of the Creative Commons Attribution (CC BY) license (http://creativecommons.org/licenses/by/4.0/). 